\title{
Analysis of the Value Dimension of the Culture of "Harmony-Integrity"
}

\author{
YU, Junli \\ Department of Sports Media and Cultural Studies \\ Xi'an Physical Education University \\ Xi'an 710068,China \\ e-mail: rainlyer@126.com
}

\begin{abstract}
The culture of "harmony-integrity" has come into shape in early Qin Dynasty and been valued as a spirit of the time. In the traditional philosophical schools, such as the Confucianism, Buddhism and Taoism, the idea of harmony and integrity is very important. In essence, this means a unification of different factors while the "harmony" and "integrity" together highlights the merging effect of various factors, which is the importance of balance in paradoxes. By document research method this paper discussed the modern value of the culture of "Harmony-Integrity" from the following five dimensions, philosophical, political, practical, cultural and aesthetical.
\end{abstract}

Keyword-the culture of "harmony-integrity"; humanistic spirit;integration of the nature and human; value dimension

\section{INTRODUCTION}

In Chinese thought and culture, "harmony-integrity" has been widely accepted and recognized as a cultural spirit, deeply rooted in almost every school of Chinese philosophies, such as the Confucianism, Buddhism, Taoism and Mohism. It is the soul of those philosophies. Open to different cultures, the culture of "harmony-integrity" is always energetic, which implicates that Chinese culture is tolerant and open-minded. As a cultural idea, it has influenced the whole development of Chinese culture, with "harmony" valued. It passes on generations after generations and has never changed essentially. In this article, the author tried to elucidate its value from philosophical, political, practical, cultural and aesthetical dimensions on the basis of its formation and development.

\section{The Formation AND DEVELOPMENT OF The Culture OF "HARMONY-INTEGRITY"}

The Chinese culture of "harmony-integrity" has a long history. Scholars generally deem that the words of "harmony" and "integrity" were originated from inscriptions on bones, tortoise shells or bronze objects. The word "harmony" originally means the accordance of sounds, while the word "integrity" the touch of lips. Afterwards, "harmony" can mean peace and euphony and "integrity" unification and blending. The two words both mean the connection of things. In the Spring and Autumn Period, the two words were used together. In The Discourses of the States, Zheng's Words, it says "Qi can unify five morals, and hence can make people safe", which means that Qi, an officer of the Shang Dynasty, can connect five morals, which are being nice to father, mother, elder brother, younger brother and child, so he can use those morals to rule the society, to make people safe. Hence, in early Qin Dynasty, the concept of "harmony and integrity" has formed and been valued as a spirit of the time.

In the Confucianism, Buddhism and Taoism, the culture of "harmony -integrity" has its role. Confucius regarded "harmony" as the core of humanistic spirit. He said "In using etiquettes, harmony is the first." He deemed that "harmony" should be the standard for ruling a country and setting an etiquette system. In dealing with relationships, he also emphasized, "Gentlemen are different but harmonious while vile men can be the same but at chaos." "being different but harmonious" acknowledges vagaries but admits that through mutual compensation, a harmonious state can be reached. This is a stark contrast with the latter sentence, which forces sameness. It also proves that "harmony" is also a principle for living and a goal to be pursued. Based on the turmoil, Mencius thought that "a favorable terrain is better than a good time, but the terrain isn't as important as unity with the people." In the three factors that matter most in a war, the harmony of the people is the most important. When you have the harmony of the people, you will have many help while vice versa. With people unifying around you, there is nothing that cannot be achieved.

Lao-tsu the founder of Taoism, came up with an idea, "Everything which embraces the sunny side must bears the shadow and while both sides meet, it is called the harmony." He thought that everything had these two sides, and the collision of the two was called harmony. The harmony was the core and foundation of the universe. Zhuang-tsu also regarded harmony as an ideal state of all pursuits. He pointed out that the shadow came from the sky and the sunny side came from the earth and the two made everything. From his point of view, gaining the natural harmony and the people's harmony makes one happy. Hence, Zhuang-tsu raised an idea of "happy to get along with people and blissful to get along well with the nature". Besides, the Taoism also proposed that people should hide their light and blend in the dust. Tempering hardness with softness and using softness to conquer hardness can also belong with the spirit of "harmony-integrity".

Buddhism also emphasizes on harmony. For example, it claims that people are formed out of five elements, bodies, feelings, thoughts, actions and knowledge. All these elements together make a man. [1]This is an important theory for Buddhism. Moreover, Buddhism also acclaims that "harmony" is the first rule for cultivation.

The three various explanations of "harmony" and "harmony-integrity" from the Confucianism, Buddhism and Taoism are due to different values of world and life. 
However, in the forming and developing process of Chinese culture, their seemingly discordance actually melted together and sucked the marrow out of each other. As it was stated in Yi Zhuan, "Keeping the balance is the most beneficial." In a broader context, these three schools extol their merits and serve their own functions and they have founded the basis of Chinese culture. The Confucianism encourages people to adjust relationships between people and reach a harmonious state, while the concepts raised by the Buddhism and Taoism are different. The Buddhism pursues a balance in not only physical but also mental state. The Taoism emphasizes on the harmonious state between people and the nature. It can be drawn that these three schools have their own values, with dissension and confluence. It is they who have created the prosperity of Chinese culture. The culture of "harmonyintegrity" has become widely recognized and accepted, which has witnessed the whole process of Chinese culture.

\section{The VAlue of The Culture of "Harmony- INTEGRITY”}

\section{A. Philosophical Dimension}

From the perspective of ontological value, "harmony" is the coexistence of heterogeneous factors, and "integrity" is the fusion of the heterogeneous factors. "Harmony-integrity" means that different factors can be unified harmoniously. The process begins from conflict, then to integration, to rebirth, and finally to a new development or new things. Therefore, "harmony-integrity" shows the unity in diversity, which is unity of different elements. And the two aspects coupled highlight the fusion effect of different elements, and emphasize the importance of harmony and coordination of contradiction.

"Harmony" is a state of nature, society and life. The book of The Discourses of the States, Zheng's Words said: "harmony makes everything." The Book of Rites noted: "harmony, so all things are." "The music is the harmony of the universe" (Book of Rites, Doctrine of the Mean); "Six music forms are to protect people from turmoil, which can be called harmony." In Lu spring and autumn · Investigation states, "harmony is the foundation of music." From these cultural classics we can see that "harmony" is the premise and basic requirement for the existence and development of things, existing state of nature, society, and life. "Harmony" is embodied in three aspects:

Firstly, the relationship between man and nature. The relationship between man and nature is the relationship of human survival and development, which people have to face at the first time. In Chinese culture, the relationship between man and nature is expressed as the relationship between man and heaven, advocates that human and the heaven should be blended. PANG Pu said: "Chinese culture do not isolate them from the relationships, nor turn man and nature against each other...... The idea of mutual unity constitutes a significant feature of Chinese culture." [2] this thinking will not make people in the relationship between human beings and the nature external, discrete, or aloof, but by all means experience nature, embrace the nature by intuition, empathy, and analogy. So, man and nature can achieve a harmonious and happy state in tolerating and accepting each other. This is completely different from the western ideology. Western scholars see the nature based on cognitive ways. The difference is, the former sees the harmony, the latter sees discretion. The former can promote the harmony between man and nature, to resolve the crisis between human and nature.

Secondly, the relationship between people. And the culture of "harmony-integrity" deems that the pursuit of a harmonious relationship between man and man, man and the society. "If you do not want it, do not give it to others," "If you want to succeed, you need to help others succeed." are interpersonal relationship criteria; "people should love their relatives and others', and should make the young strong, the kids smart, and the pity, widowed, orphaned and alone cared." is what the ancient people and modern ones yearn for.

Once again, the relationship between your body and mind. The harmonious development of reason and emotion enables us to solve the tension and conflict deep inside your heart. We can do it disinterestedly either by gain or loss, and advance and retreat accordingly. In the construction of contemporary humanistic spirit, we should tap the culture of "harmony", focus on the emotion, and emphasize the positive elements of emotion and reason of harmonious development, to alleviate the lack of emotion in a market economy society, to guide and cultivate good feelings, and strengthen the training of the poor control of good feelings and emotional catharsis.

\section{B. Political Dimension}

On the real political operation planning level, traditional society had all kinds of methods of realizing harmony. The ancients tried to use them in social and political life, to regulate people's behavior and to attain peace, harmony. It is of great significance to us today for the construction of harmonious society. The culture of "harmony-integrity" also helps to keep the way of thinking from a bigger picture, which enriches the spiritual connotation of the concept of sustainable development. It embodies the overall idea of simple overall dialectics and system. In the new period of building a well-off society, we improve the overall systematic concept, make it more scientific, and apply it in practice. Finally, a comprehensive, coordinated, and sustainable concept of scientific development value will be formed, which is a contemporary performance of the cultural force of "harmony-integrity".

\section{Practical Dimension}

From a practical perspective, the culture of "harmonyintegrity" is a kind of value principle of the regulation of social relations. According to this principle, all aspects of social life and all kinds of relations constitute an organic whole, which is interrelated and interactive. Only when the various elements and relationships are balanced, connected, and orderly coordinated, can an effective operation of society be achieved. And the culture of "harmony-integrity" thinks that the existence of things, and their development cannot do without the harmony and integrity of other things. Thus, when people deal with things or the problems, should take relative harmonious ways, and oppose the dictated practices.

The culture of "harmony-integrity" is a reasonable practice, which emphasizes on ways of doing things in daily life. For individuals, everyone is living in social relations. 
Interpersonal harmony is the key to physical and mental pleasure and success. "Harmony" improves you, and vice versa. In a word, "harmony" is the prerequisite for cooperation, and cooperation in turn can create harmonious interpersonal atmosphere and competitive environment, and make the two sides reach a "win-win". As Mr. FENG Youlan at the University of Pennsylvania in the United States to explain the mystery of the Chinese culture: "harmony is to reconcile the different in order to achieve the harmonious unity...... A well-organized society, is a harmonious unity, in which all kinds of ability, occupation, all people have the appropriate location, play a proper role, everyone feels equally satisfactory, and there is no conflict with each other." [3]Realizing the harmonious development of utilitarian and ethics in the market economy society, is a full presentation of contemporary ideological value.

\section{Cultural Dimension}

Over the past hundred years, we have ignored the spirit of traditional culture of ours. Especially in the past three decades, we have been unable to learn from the traditional culture to make cultural innovation abreast with the times. From the inside environment of social culture, the economic rise has led to the moral crisis of the whole society; from the external environment, the lack of fascinating culture and a relevant value system, an economic rise is often regarded as a terrible thing or a threat. In today's world of rapid change, the loss of autonomy and the sink in the modernity imagination can only be dominated by modernity.

And the culture of "harmony-integrity" is keeping pace with the times and open to the outside world. This system is a kind of resources of thoughts, which can give us a method, an attitude. Open our arms to draw national and world cultural essence, and removing dregs, can help the establishment of new cultural value system. According to the traditional enlightenment, if we want to create a new social order, or a modern civilization, it is necessary for us to go through introspection and creative transformation of traditional cultural resources -- both selectively absorb the traditional cultural resources, but also to accept the foreign resources to expand our own cultural architecture. As we know, the core of Western civilization is the spirit of science, and the core of Chinese civilization is the humanistic spirit. Learning from and absorbing the spirit of science of the Western civilization, and carrying forward the humanistic spirit of Chinese traditional culture, we can effectively complement each other. This is of important significance for China entering the rank of modernization and globalization.

\section{E. Aesthetical Dimension}

The beauty of neutralization and harmony is an important aesthetic category of Chinese ancient literature and art. [4] The aesthetic pursuit of the "beauty of neutralization" has its unique and abundant theoretical connotation, from a life experience and artistic appreciation. Zuo Zhao Gong Twenty Years elucidated the content of "neutral": " big and small, short and long, quick and slow, hard and soft, high and low, out and in, dense and loose, etc. all compensate for each other. A gentleman listens, with a flat heart. Mental peace and stability is achieved, so the Classics of Poetry said 'harmonious sound will never be not flawed'. If you put water into water, who is willing eat that? If the music has only one tone, who would want to hear it?" [5] The opposite elements of harmonious thinking comes from The Book of Changes: "the miscellaneous words can be called a verse"; "to change the content and master the complexity, anyone can go through the world of literature". The Discourses of the States noted: "Everything comes from harmony, but the sameness disturbs further development." This is a summary of the first ancient sages who understand all things and form their personal theories. "Harmony" is the understanding of ancient philosophers on the nature. They get inspiration from the natural world in essence, and become aware of the nature of social life, and art should also be harmonious. The ancient Chinese aesthetics of "beauty of neutralization" values is deeply rooted in this. As a kind of aesthetic ideal, "the beauty of neutralization" is the highest ideal of literary and artistic beauty, which has inspired the artists to write many ancient and modern literatures. Those masterpieces are harmonious, elegant, and mellow, which can make the human souls purified, the emotion sublimed, and exerts an extremely far-reaching impact on the Chinese aesthetic psychological structure.

\section{CONCLUSION}

To sum up, the culture of "harmony-integrity" shows the deep wisdom of survival and vitality in the process of modernization of Chinese culture. When the Chinese culture faces the predicament of modern civilization, between man and nature, man and society, among contradictions and problems, the cultural performance of "harmony-integrity" displays its unique value. In this context, as long as we continuously study the culture of "harmony-integrity" from a multidimensional perspective, Chinese culture and spirit, embodying the "harmony" idea, in resolving the conflict, will bloom splendor, walk towards the world, and become the worldly recognized spirit.

\section{ACKNOWLEDGMENT}

The author gratefully acknowledge the financial support of National Social Science Foundation of China(Grant No.12XZW010),the Ministry of education Humanities and Social Science Foundation of China(11YJC751107).

\section{REFERENCES}

[1] Great Treatise on the Perfection of Wisdom:vol.31.

[2] [P.Pang, Humanistic spirit of Chinese culture,Guangming Daily, 1986,1,6.

[3] Y.L.Feng,A brief history of Chinese Philosophy,bejing,The Peking University Publishing House, 1996,p. 150.

[4] L.M.Weng,The ritual and music culture and the poetic discourse,chengdu,Bashu Publishing House, 2007,p. 204-214.

[5] The outhodox exposition of the Zuozhuan on the Chunqi: vol.49. 